\title{
El reportaje de infoentretenimiento: evolución del género en las televisiones generalistas en España (1990-2020)
}

\author{
The infotainment report: evolution of the genre in the general- \\ interest television channels in Spain (1990-2020)
}

\author{
García-Avilés, J. A. ${ }^{1}$ \\ Recibido: 20-01-2021 - Aceptado: 15-08-2021 \\ https://doi.org/10.26441/RC20.2-2021-A9
}

\begin{abstract}
RESUMEN: El macrogénero del infoentretenimiento televisivo comprende diversos géneros y, con independencia de la etiqueta con la que se defina cada uno, ofrece un amplio abanico de variaciones y combinaciones que se reinventa constantemente. El reportaje de infoentretenimiento implica una mutación del género puramente informativo, ya que la representación de las vidas cotidianas se ha convertido en un gran espectáculo televisivo con rasgos propios. Esta investigación identifica 29 programas de reportajes de infoentretenimiento emitidos en la televisión generalista en España entre 1990 y 2020 y estudia su evolución. Los canales que han emitido un mayor número de reportajes de infoentretenimiento son La Sexta (once programas) y Cuatro (ocho), seguidos por La 1 de TVE (cuatro), Antena 3 (tres) y Telecinco (tres). Los resultados muestran que los reportajes de infoentretenimiento, producidos en su mayoría por productoras externas a las cadenas, presentan una estética con estilo documental, abordan historias de la gente ordinaria, conceden protagonismo al reportero, apelan a la emoción y potencian la hibridación del género.
\end{abstract}

Palabras clave: televisión; géneros televisivos; infoentretenimiento; reportaje; hibridación; información televisiva; sensacionalismo; programa de televisión.

ABSTRACT: The macro-genre of TV infotainment comprises several genres and, regardless of the label under which each is defined, offers a wide range of variations and combinations that are constantly being reinvented. The infotainment report implies a mutation of the purely informative genre, as the representation of everyday lives has become a major television spectacle with its own characteristics. This research identifies 29 infotainment programmes broadcast on generalist television in Spain between 1990 and 2020 and analizes their evolution. The channels that have broadcast the highest number of infotainment reports are La Sexta (eleven programmes) and Cuatro (eight), followed by La 1 de TVE, Antena 3 (three) and Telecinco (three). The results show that infotainment reports, most of which are produced by companies outside the channels, have a documentary-style aesthetic, deal with stories about ordinary people, give the reporter a leading role, appeal to emotion and promote the hybridisation of the genre.

Keywords: television; television genres; infotainment; TV report; hybridization; television information; sensationalism; television program.

\footnotetext{
1 José Alberto García-Avilés es Doctor en Comunicación por la Universidad de Navarra y Profesor Titular del Departamento de Ciencias Sociales y Humanas de la Universidad Miguel Hernández de Elche. Imparte clases en el programa de Máster en Innovación en Periodismo. Su investigación se centra en la innovación periodística y en la calidad de los medios. Es miembro de la junta directiva de la Asociación Española de Periodística y de la AE-IC. jose.garciaa@umh.es, http://orcid.org/0000-0001-7854-3476
} 


\section{Introducción: El infoentretenimiento en la información televisiva}

La multiplicación del número de canales y la creciente competencia incrementa la presión que los índices de audiencia ejercen sobre los espacios informativos. En España con el nacimiento de las cadenas privadas a finales de los noventa, la información televisiva empezó a someterse a los criterios de rentabilidad análogos a los que rigen en los contenidos de entretenimiento (Ortells, 2011). Por tanto, los espacios informativos incorporaron como criterio de eficacia su capacidad para entretener a la audiencia, lo que promovió la expansión del género infotainment, traducido al castellano como infoentretenimiento, "un vocablo que reúne dos funciones relativas a los medios de comunicación tradicionalmente distantes e incluso opuestas, como son la información y el entretenimiento" (Berrocal, 2017: 37).

Sobre el concepto de "infoentretenimiento" televisivo existe un consenso en la literatura que subraya la hibridación de géneros (Gordillo et al., 2010), combinando los elementos propios de la información con aquellos que caracterizan a los géneros de entretenimiento, promoviendo las emociones, el dramatismo o el humor (Berrocal, Campos y Torres, 2015; García-Avilés, 1999) y potenciando la espectacularización de los contenidos (Salgado Losada, 2011). En este sentido, el concepto de "espectáculo" se refiere a la representación producida para ser vista y disfrutada por los receptores de esta -receptores que a menudo son también copartícipes de dicho espectáculo, ya sea una obra teatral, un concierto o un programa televisivo (Casero y Marzal, 2011; González Requena, 1985), mientras que la "espectacularización" alude a la falsificación de la representación, la perversión del espectáculo. Siguiendo a Imbert (2008), la espectacularización es uno de los factores que han transformado la televisión actual en un proceso de telerrealidad y teleidentidad, ha alterado sus funciones sociales, ha difuminado la frontera entre información y ficción, y ha dañado los valores éticos, estéticos, morales y simbólicos, implantando el dominio del simulacro.

El infoentretenimiento es una tendencia transversal sobre la representación de la realidad en distintos formatos televisivos. Los formatos son variaciones formales de los géneros, con cierta gradación y relación de dependencia de uno respecto al otro (Saló, 2003). Sin embargo, como subraya Gordillo (2009: 42), “en la hipertelevisión se observa una subordinación de los géneros a la lógica de los formatos, debida, entre otras razones, a las condiciones en las que operan las industrias culturales, y a las complicadas relaciones entre beneficio, éxito y competencia entre cadenas de televisión".

De acuerdo con Salgado (2010: 62-63), el infoentretenimiento es un macrogénero televisivo. Al elaborar una taxonomía sobre los distintos géneros que integran el infoentretenimiento, cabe diferenciar:

- Infoentretenimiento en los informativos diarios (Luzón y Ferrer, 2008)

- Reportajes de infoentretenimiento (Domínguez-Quintas y Arévalo-Iglesias, 2020; Gómez-Rubio, López-Vidales, y Blanco-Huerta, 2020)

- Magazines de infoentretenimiento (Ortells-Badenes, 2015)

- Pseudoperiodismo de humor o infosátira (García-Avilés, 1999; Valhondo, 2011)

Además, el infoentretenimiento recibe la influencia del macrogénero de la telerrealidad, que comprende géneros como el dating-show, crime, makeover, docudrama, docuserie, talent y reality show, entre otros (Nabi, 2007; Ramírez y Gordillo, 2013).

En definitiva, el infoentretenimiento comprende diversos géneros y, con independencia de la etiqueta con la que se defina cada uno, ofrece un amplio abanico de variaciones y combinaciones que se reinventa constantemente, ya que "los contenidos y las formas narrativas se seleccionan teniendo como criterio supremo el impacto que puedan causar en la audiencia, en lugar de la capacidad para suministrar información relevante, de forma rigurosa" (García-Avilés, 2007: 51). 
Numerosos estudios (Berrocal, 2017; Casero y Marzal, 2011; Ortells, 2011) han evidenciado el predominio del infoentretenimiento en España en la última década. Sus diagnósticos resultan esclarecedores para entender la progresiva evolución del infoentretenimiento televisivo, que se nutre de los elementos de morbo, emoción y espectáculo aplicados a los relatos sobre la gente corriente (Ortells, 2015). Los contenidos se aligeran y lo trivial y lo próximo reclaman la atención de la audiencia inmersa en la cultura del espectáculo. La calidad informativa se reduce, salvo raras excepciones, en favor del sensacionalismo y el entretenimiento (Segado-Boj, 2015). La teatralización de la esfera privada que promueven los géneros del infoentretenimiento contribuye a que la vida cotidiana se transforme en un producto de consumo (Casero y Marzal, 2011).

En el ámbito académico se ha consolidado la investigación sobre el infoentretenimiento, teniendo en cuenta el peso que este macrogénero ha ido adquiriendo en las parrillas de las televisiones en España. Cabe destacar los trabajos de Berrocal et al. (2014), Brants (1998), Carrillo (2013), Casero y Marzal (2011), García-Avilés (2007), Gómez (2006), Lozano (2004), Ortells (2011, 2015), entre otros, que han investigado los rasgos estilísticos y temáticos que caracterizan al infoentretenimiento en los espacios informativos, reportajes y documentales, así como en formatos afines.

Este trabajo identifica de manera sistemática los programas de reportajes de infoentretenimiento emitidos en la televisión generalista en España entre enero de 1990 y diciembre de 2020, con objeto de estudiar las principales características del género. Se trata de una investigación pertinente porque hasta la fecha no existen trabajos que identifiquen y analicen exhaustivamente los reportajes de infoentretenimiento emitidos en los canales de televisión españoles.

\section{Marco referencial: el reportaje de infoentretenimiento}

El reportaje televisivo es un género informativo que permite la experimentación con diferentes formatos y narrativas, y mayor originalidad en su planteamiento y presentación (Gómez-Rubio, López-Vidales y Blanco-Huerta, 2020). Este género guarda una cierta relación con el documental, con el que mantiene un intercambio fructífero. También se vale de numerosos recursos narrativos provenientes de las producciones de ficción (Vázquez La Hoz y Román Portas, 2013). En este contexto, el reportaje audiovisual es un género camaleónico, resultado de un proceso de hibridación en el que comparte unas fronteras cada vez más borrosas con la información, el entretenimiento y la ficción.

Las cadenas británicas emplean el término "entretenimiento basado en hechos" (factual entertainment) para aludir a la representación de acontecimientos interpretados por sus propios protagonistas (Langer, 1998). En este sentido, el discurso del infoentretenimiento utiliza los hechos como un ingrediente más. Los productores recurren a la técnica de certificar la verdad de lo que se muestra en la pantalla. Las alusiones a "Esto sucedió en la realidad", "basado en una historia real..." obvian que muchos de estos géneros ofrecen una representación de la realidad o incluso emplean recreaciones basadas en los hechos (Domínguez-Quintas y Arévalo-Iglesias, 2020).

Los programas de reportajes sobre la gente corriente no son un fenómeno nuevo en España. Existen antecedentes en los años ochenta, tales como Por tierras lejanas o La aventura humana, ambos de TVE. El origen del género puede situarse en el lanzamiento en 2001 del programa Mi cámara y yo en Telemadrid. Elena Sánchez, exdirectora de informativos de la televisión autonómica, subraya: "Inspirada en una serie de programas de TV3 que retrataban la sociedad en la que vivimos, puse en marcha nuevos formatos sobre las cosas que nos rodean, entre ellos Mi cámara y yo. Compramos cámaras pequeñas y menos intrusivas para colarnos en más sitios" (Cit. en Pérez-Lanzac, 2010).

En esta investigación, entendemos por reportaje de infoentretenimiento el género caracterizado por una supuesta autenticidad que fomenta la conexión del espectador con la vida de la gente corriente, 
a través de la implicación del reportero, quien induce a que los personajes aborden los asuntos que les interesan, mediante una realización de estilo documental que recoge las acciones y situaciones de los personajes.

En buena medida, la proliferación del reportaje de infoentretenimiento se debe a su reducido coste, más económico que un episodio de una serie de ficción. Según Pérez-Lanzac (2010), Españoles en el mundo costaba menos de 50.000 euros por emisión. Es significativo que, en 2010, dicho programa obtuvo mejores datos de audiencia que tres ficciones mucho más costosas con las que competía: Hospital Central (Telecinco), Hay alguien ahi (Cuatro) y Los protegidos (Antena 3). En este contexto, se incrementan los formatos low-cost que apelan a la audiencia mediante técnicas como un ritmo de edición vertiginoso, frecuentes movimientos de cámara y grabación con cámara al hombro (Domínguez-Quintas y Arévalo-Iglesias, 2020).

Como argumenta John Corner (2002), la televisión ha entrado en una cultura post-documental que transforma las prácticas, formas y funciones predominantes en los reportajes tradicionales. El reportaje de infoentretenimiento plantea consideraciones éticas al abordar cuestiones relacionadas con el sensacionalismo, la manipulación o la desinformación sobre la realidad (García-Avilés, 2009; Redondo García y Campos Domínguez, 2015). De hecho, los estándares éticos periodísticos tienen cabida en estos reportajes ya que, "los periodistas mantienen como aspiración el respeto a la verdad y al rigor, así como la obligación de separar la información de la opinión y de la publicidad; el entretenimiento, por su parte, no tiene más normas que el respeto a la ley" (Redondo García y Campos Domínguez, 2015: 79).

\section{Objetivos y metodología}

Este estudio persigue dos objetivos principales:

a) Identificar los programas de reportajes de infoentretenimiento emitidos en la televisión generalista en España en las tres últimas décadas (1990-2020).

b) Analizar cómo han evolucionado las características del género durante este periodo.

En función de dichos objetivos, se plantean dos preguntas de investigación:

PI1: ¿Cuáles son los programas que pueden considerarse reportajes de infoentretenimiento emitidos por las cadenas generalistas en el periodo objeto de estudio?

PI2: ¿Qué rasgos caracterizan a este tipo de reportajes de infoentretenimiento, en contraposición al reportaje informativo?

Mediante una revisión completa de la programación publicada en los diarios El Mundo y El País, y en Ver Tele y FórmulaTV, se elaboró una base de datos de los programas de reportajes emitidos en los canales de televisión generalista en España, desde el 1 de enero de 1990 hasta el 31 de diciembre de 2020. La elaboración de esta base de datos y la aplicación de los parámetros que integran la definición de reportaje de infoentretenimiento permitió identificar los espacios encuadrables en este género emitidos por cada canal generalista (Antena 3, Telecinco, La 1, Cuatro y La Sexta) y analizar sus principales rasgos.

En el análisis se empleó un enfoque analítico-descriptivo, mediante la recopilación de fuentes bibliográficas y el análisis de reportajes alojados en repositorios y en los servicios a la carta de las televisiones (Atresplayer, Mitele y RTVE a la carta), sin ánimo de exhaustividad, con objeto de detectar sus principales características, conocer su evolución y examinar la relación entre la función de informar y entretener. En cada programa identificado se analizaron dos emisiones completas en distintas temporadas -salvo en aquellos casos en los que no se pudo acceder a ellas-. La ficha de 
análisis incluía los siguientes parámetros: programa, cadena, fecha de emisión, duración, productora, cuota de audiencia, equipo, título del reportaje, tema, presencia del reportero en cámara, bloques de la estructura narrativa, ritmo de edición, uso de cámara oculta, uso de la música, rotulación, elementos audiovisuales, grafismo y apelación a las emociones.

\section{Los reportajes de infoentretenimiento en las cadenas generalistas (1990-2020)}

Los resultados se basan en el análisis de los 29 programas objeto de estudio que se resumen en la Tabla 1 y se desarrollan en los siguientes epígrafes.

Tabla 1. Análisis de los programas de reportajes de infoentretenimiento (1990-2020)

\begin{tabular}{|c|c|c|c|c|c|}
\hline Programa & Cadena & Inicio & Cancelación & Producción & $\begin{array}{c}\text { Audiencia } \\
\text { media }\end{array}$ \\
\hline Espejo público & Antena 3 & Octubre 1996 & Dic. $2006^{*}$ & Antena 3 & $21 \%$ \\
\hline Al descubierto & Antena 3 & Marzo 2002 & Junio 2002 & El Mundo TV & $22 \%$ \\
\hline En tierra hostil & Antena 3 & Enero 2015 & Abril 2015 & Verte & $14 \%$ \\
\hline A corazón abierto & Telecinco & Enero 2003 & Febrero 2003 & El Mundo TV & ND \\
\hline Diario de... & Telecinco & Mayo 2004 & Agosto 2014 & SALTA & ND \\
\hline El infiltrado & Telecinco & Junio 2010 & Julio 2010 & $\begin{array}{l}\text { Visiona TV y } 7 \text { y } \\
\text { Acción }\end{array}$ & ND \\
\hline Comando actualidad & La 1 & Marzo 2008 & Sigue en emisión & TVE & $11 \%$ \\
\hline Españoles en el mundo & La 1 & Febrero 2009 & Sigue en emisión & New Atlantis & $10,5 \%$ \\
\hline Destino: España & La 1 & Febrero 2010 & Marzo 2013 & I.C. Comunicación & $7,2 \%$ \\
\hline El paisano & La 1 & Mayo 2018 & Enero 2021 & Brutal Media & $9,2 \%$ \\
\hline Ola, Ola & Cuatro & Agosto 2008 & Sept. 2011 & Molinos de Papel & $9,8 \%$ \\
\hline Callejeros & Cuatro & Nov. 2008 & Marzo 2014 & Molinos de Papel & $9,35 \%$ \\
\hline Callejeros viajeros & Cuatro & Abril 2009 & Sept. 2013 & Mandarina & $5,6 \%$ \\
\hline 21 días & Cuatro & Enero 2009 & Julio 2016 & Boca Boca & $9,45 \%$ \\
\hline Conexión Samanta & Cuatro & Nov. 2010 & Febrero 2016 & Boca Boca & $7,7 \%$ \\
\hline REC Reporteros & Cuatro & Abril 2010 & Enero 2011 & La Quimera & $8,2 \%$ \\
\hline $\begin{array}{l}\text { ¿Qué hago } \\
\text { yo aquí? }\end{array}$ & Cuatro & Abril 2013 & Mayo 2013 & Mandarina & $5,1 \%$ \\
\hline En el punto de mira & Cuatro & Julio 2016 & Marzo 2021 & Cuarzo & $6,3 \%$ \\
\hline Vidas anónimas & La Sexta & Nov. 2007 & Junio 2012 & Mediapro & ND \\
\hline $\begin{array}{l}\text { Historias con denominación } \\
\text { de origen }\end{array}$ & La Sexta & Octubre 2009 & Diciembre 2009 & Mediapro & ND \\
\hline ¿Quién vive ahí? & La Sexta & Enero 2010 & Marzo 2012 & Globomedia & $11,3 \%$ \\
\hline Equipo de investigación & La Sexta & Enero $2011^{\star \star}$ & Sigue en emisión & Atresmedia & $6,9 \%$ \\
\hline Salvados & La Sexta & Febrero 2008 & Sigue en emisión & $\begin{array}{l}\text { Producciones } \\
\text { del Barrio }\end{array}$ & $11,3 \%$ \\
\hline Encarcelados & La Sexta & Sept. 2013 & Nov. 2013 & Atresmedia & $9,6 \%$ \\
\hline Enviado especial & La Sexta & Febrero 2016 & Dic. 2019 & Atresmedia & $7,7 \%$ \\
\hline Lo de Évole & La Sexta & Febrero 2020 & Sigue en emisión & $\begin{array}{l}\text { Producciones } \\
\text { del Barrio }\end{array}$ & $10,4 \%$ \\
\hline LAB: Tal como somos & La Sexta & Dic. 2013 & Enero 2014 & Mediapro & $6,4 \%$ \\
\hline Dentro de... & La Sexta & Mayo 2017 & Junio 2017 & Verte & $6,2 \%$ \\
\hline Natural & La Sexta & Octubre 2020 & Dic. 2020 & Atresmedia & $6,8 \%$ \\
\hline
\end{tabular}

*Espejo Público se convirtió en un magazín diario de actualidad.

** Equipo de investigación comenzó emitiéndose en Antena 3 y desde enero de 2012 se emite en La Sexta.

Fuente: elaboración propia con datos de FormulaTV, Kantar, Barlovento y otros. 


\subsection{Antena 3 TV}

Cabe considerar a Espejo Público, estrenado el 20 de octubre de 1996, como el primer programa de reportajes de infoentretenimiento en una cadena privada. El espacio, inicialmente dirigido y presentado por Pedro Piqueras, se emitía los domingos. En octubre de 1998, Piqueras fue relevado por Roberto Arce, hasta agosto de 2002. En septiembre de ese año, Sonsoles Suárez se hizo cargo de la presentación. En ocasiones también lo presentaron Soledad Arroyo, Lourdes Maldonado y Lydia Balenciaga. Durante sus diez años de emisión Espejo Público obtuvo una audiencia media del 21\%. El 11 de diciembre de 2006, se transformó en un magacín matinal.

Los equipos del programa elaboraron más de 3.300 reportajes y cubrieron historias en América, Asia, Europa, África, Oriente Medio y la Antártida. Estuvieron presentes en la guerra de Kosovo, el paso del huracán Katrina por Nueva Orleans o el viaje del buque oceanográfico Hespérides a la Antártida; entrevistaron a personajes como Leni Riefenstahl, Giorgio Armani, Madona, Rostropovich o Stephen Hawking. Espejo Público obtuvo tres premios Antena de Oro y dos TP de Oro, Laurel de Oro (2004) de la Asociación de Prensa, Radio y Televisión de México, y Mejor documental de noticias del Festival de Nueva York (2004).

Antena 3 apostó por un estilo sensacionalista en diversas investigaciones mediante el uso de la cámara oculta. El 18 de marzo de 2002 la cadena lanzó Al descubierto, un espacio de investigación presentado por Santiago Acosta y producido por Melchor Miralles, de la productora El Mundo TV. El programa utilizó cámaras ocultas para captar testimonios exclusivos e investigar asuntos polémicos. Su estreno ofreció la investigación de una periodista infiltrada en el certamen de Miss España, quien compartió habitación con Miss Almería, la joven que ganó el certamen, y denunció presuntas irregularidades.

Al descubierto combinaba la emisión de un reportaje grabado mediante cámara oculta con un debate con tertulianos y protagonistas en plató. Durante sus tres meses de emisión, cosechó una audiencia media del $22 \%$ en 18 entregas. Al descubierto abordó temas como las estafas de curanderos y videntes telefónicos o la corrupción en el fútbol y se consolidó como un formato de infoentretenimiento rentable (Mercado, 2005).

Tras un amplio paréntesis en el que Antena 3 dejó de incluir el género en su parrilla, en enero de 2015 la cadena lanzó En tierra hostil, presentado por Alejandra Andrade y Jalis de la Serna, y producido por Verte. Los dos reporteros protagonistas entrevistaban a ciudadanos españoles que residen en lugares complicados como Venezuela, Ucrania o Corea del Norte. Los once reportajes emitidos hasta el 1 de abril de 2015 cosecharon una media del 14\% de cuota de pantalla.

Los reporteros de En tierra hostil lograron acceder a lugares y situaciones complicadas, como el control gubernamental en Corea del Norte o la presión que somete el régimen de Nicolás Maduro a los líderes opositores. El segundo programa, titulado 'Marruecos', fue criticado por distintas instancias en Ceuta que lo calificaron de 'sensacionalista y manipulador'. Andrade y de la Serna aportaron un valor informativo diferencial mediante su aparición en cámara y el uso de la primera persona, convirtiéndose en testigos de la realidad que contaban con un rol protagonista.

\subsection{Telecinco}

Telecinco inauguró el reportaje basado en cámara oculta con A corazón abierto el 23 de enero de 2003, presentado por Jordi González. El programa, también producido por El Mundo TV, adoptó una estructura similar a la de Al descubierto de Antena 3. La emisión de un reportaje grabado por periodistas infiltrados iba acompañada por un debate que moderaba González. Según la publicidad promocional, "el programa se adentra en la trastienda de los famosos para destapar las argucias 
perpetradas por algunos protagonistas en su particular comercio con sus vidas privadas: romances inexistentes, montajes de exclusivas millonarias o ventas de acontecimientos familiares y conyugales previo pago" (Vertele, 2003). Jordi González sostiene que pretendía "quitar la máscara a todos aquellos famosos capaces de inventar historias absolutamente delirantes para salir en los medios". Para el presentador, la cámara oculta es "un elemento tremendamente útil, es un testigo directo de cualquier engaño, un adelanto siempre que se utilice con fines dignos" (Vertele, 2003). La cadena de Mediaset retiró el espacio el 20 de febrero de 2003.

En la línea de reportajes a cargo de un rostro famoso, Telecinco lanzó en abril de 2004 Diario de..., presentado por Mercedes Milá, dirigido por Alberto Muñiz y producido por SALTA. El programa surgió a raíz de dos investigaciones del libro "El año que trafiqué con mujeres", del periodista Antonio Salas, que Telecinco emitió con buenos registros de audiencia. La etapa de Diario de... en Telecinco abarca desde el 31 de mayo de 2004 hasta enero de 2011, cuando pasó a emitirse en Cuatro, tras la fusión de Mediaset con el canal de Prisa TV. El espacio se canceló en agosto de 2014.

Mercedes Milá, entonces también presentadora del reality Gran Hermano, se dedicaba a destapar todo tipo de irregularidades mediante entrevistas implacables. Uno de los programas más polémicos fue 'Una obsesión: la belleza', emitido el 19 de julio de 2006. Milá abordó la historia de dos jóvenes anoréxicas y denunció las prácticas de clínicas especializadas en tratamientos estéticos que aceptaban pacientes que no necesitaban tratamiento, de quienes obtenían enormes beneficios.

Javier Sardá se encargó de pilotar El infiltrado en Telecinco. En este formato, estrenado el 29 de junio de 2010, Sardá viajaba a distintos países para vivir experiencias de primera mano junto a sus protagonistas: patrulló en una fragata de la Armada por aguas de Somalia, fue testigo del lanzamiento de un transbordador de la NASA, y compartió con el torero El Juli su gira por Sudamérica. De este modo, El infiltrado pretendía mostrar una realidad a la que muy pocos tienen acceso, al introducir al presentador como un personaje más en la historia. Tuvo seis entregas y no cosechó buenas audiencias.

\subsection{La 1}

La televisión pública estatal apostó por una línea de reportajes de infoentretenimiento centrada en las historias humanas. El 11 de marzo de 2008, la Dirección de Magacines y Actualidad de TVE estrenó Comando Actualidad, dirigido por David Moncasi. El programa de producción propia, que se emite hasta la fecha, incluye cuatro reportajes de entre 8 y 25 minutos cada uno y aborda las distintas perspectivas de un tema a través de la mirada de cuatro reporteros. La clave del éxito es el trabajo coral de los periodistas que muestra lo que ocurre mediante un estilo personal y espontáneo. Durante el verano se denomina Comando al sol, con temas vinculados al periodo estival.

El equipo del programa se fue modificando a lo largo de los años. En la actualidad lo conforman Juan Carlos Cuevas, Sara Lozano, Mariló Montero, Teresa Perales, Silvia Sánchez, Mónica Hernández, Mila Payo y Dani Galindo. En marzo de 2018 Comando Actualidad celebró su décimo aniversario en La 1, que supuso la emisión de 500 reportajes con más de 3.600 historias. Ha obtenido una quincena premios, entre ellos el Iris de la Academia de Televisión.

La reportera Mónica Hernández explica cómo construye el reportaje: "Intentamos plasmar la realidad como si fuéramos un espejo, sin olvidar el sentido crítico, la honestidad y la responsabilidad social que debe caracterizar al periodismo" (cit. en Torrús, 2012). Comando Actualidad fue uno de los primeros en contar los desahucios al comienzo de la crisis y cómo han cambiado las bodas o el sector del maquillaje en los tiempos del Covid-19. "Para tomar el pulso de la sociedad es imprescindible pasar mucho tiempo en la calle, hablar con la gente, detectar sus preocupaciones y así, un tema te va llevando a otro", señala Hernández, y apunta que lo principal es "no juzgar a nadie": 
"Hacemos las preguntas necesarias, y a través de las respuestas de los protagonistas, los espectadores deben extraer sus propias conclusiones" (cit. en Torrús, 2012).

Otra de las claves de Comando Actualidad es la empatía con los protagonistas y la profesionalidad. "No nos podemos proteger frente a la dureza de la realidad ni las injusticias. Nosotros sacamos la cámara, y en ese momento, empieza la vida. Vamos detrás de ella", apostilla Sánchez. La audiencia media del programa no ha descendido del 8\%. El máximo histórico se sitúa en agosto de 2017 cuando registró un 14,5\% con Comando al Sol. Hasta el 16 de diciembre de 2020, con la emisión de 'El amor en los tiempos del Covid', se han emitido 14 temporadas, por lo que es el espacio de reportajes de infoentretenimiento más longevo vigente en la actualidad.

En la misma línea de conectar emocionalmente con la gente ordinaria, el 19 de febrero de 2009, La 1 estrenó Españoles en el mundo, producido por New Atlantis, que narra la vida de compatriotas en distintas ciudades del planeta. El espacio carece de un reportero protagonista; de hecho, el periodista no suele aparecer en cámara, y a través de la voz en off emplea un estilo ágil. El programa logró un $20,6 \%$ de cuota de pantalla en 2010, el récord del formato. El último programa de la temporada 13 dedicado a Venecia y Trieste, se emitió el 24 de julio de 2020 y obtuvo un 7,5\%. En 2021 continuaba en antena.

Según su directora, Carmen Domínguez, el formato se basa en tres elementos: "el documental puro y duro; ser un programa de viajes y no de turismo, y destacar el elemento humano" (cit. en Pérez-Lanzac, 2010). La gente necesita viajar, aunque sea desde el salón de su casa, y le fascina ver a compatriotas que muestran rincones de la ciudad en la que residen por amor, trabajo o aventura. Desean conocer sus casas, sus parques favoritos, sus tareas cotidianas, los centros de ocio.

Españoles en el mundo fue criticado por dar una imagen exageradamente positiva de esos españoles que muestran en el extranjero. ¿Por qué a todos los españoles les va tan bien y parecen tan felices? ¿Acaso no hay destinos poco atractivos o españoles a los que les vaya mal? Según Domínguez, "es un programa blanco que busca sacar el lado amable y atractivo de los destinos" (cit. en Pérez-Lanzac, 2010) y volcarse en la gente insólita: "Los personajes que mejor funcionan son los simpáticos, seguidos de los luchadores. Gustan porque transmiten valores positivos. Venden ilusión, esperanza y superación. Han perseguido un sueño y lo han conseguido" (Ibidem).

En febrero de 2010, La 1 estrenó Destino: España, basado en reportajes que mostraban el país a través de los ojos de los inmigrantes y turistas extranjeros. El espacio explotaba, a la inversa, la moda de los formatos de reportajes con cámara en mano que siguen a emigrantes españoles por todo el planeta y recorría diversos lugares emblemáticos del país a través de la mirada de los extranjeros que eligen España como destino. Incluía los testimonios de quienes han elegido España como lugar de residencia y reflejaba su proceso de adaptación a la cultura y al modo de vida en distintas comunidades autónomas.

Destino: España se inspiró en Un lloc estrany, Un lugar extraño, un formato de las televisiones autonómicas TV3, Telemadrid, ETB, Canal Sur y Aragón TV. El espacio se emitía justo después de Españoles en el mundo, completando así un prime time temático en La 1. Cada programa se centraba en una comunidad autónoma y contaba las historias de seis o siete personas llegadas a España procedentes de todas partes del mundo. Los protagonistas pasean por la localidad en la que residen mientras cuentan cómo viven, por qué vinieron, cómo se han integrado y las diferencias entre España y su país de origen. Fue cancelado en 2013, tras tres temporadas.

La 1 dio una vuelta de tuerca a los reportajes de infoentrenimiento con el lanzamiento de El paisano en mayo de 2018, producido por Brutal Media. Hasta la fecha se han emitido cinco temporadas, cada una presentada por un comunicador (Pablo Chiapella, Eva Hache, Edu Soto, Jorge Cadaval y 
Leo Harlem) que narra la vida en pueblos de menos de mil habitantes. El objetivo de El paisano es conocer las historias de sus habitantes durante cuarenta y ocho horas, para crear un monólogo que presentará en el teatro durante la última noche. De esta manera, los paisanos son los protagonistas. El monólogo final combina el humor del presentador con escenas emblemáticas de su paso por la localidad. El espacio, basado en el formato danés Comedy on the Edge, es la versión nacional de $E l$ foraster de TV3. La cuota de pantalla de El paisano disminuyó progresivamente, desde su estreno $(12,2 \%)$ hasta el espacio emitido el 17 de diciembre de $2020(7,1 \%)$.

\subsection{Cuatro}

Uno de los máximos exponentes del reportaje de infoentretenimiento es Callejeros. Este formato, que empezó llamándose Vidas Contadas, arrancó en noviembre de 2005 con el programa 'Simplemente María', sobre el nacimiento de una niña. Como afirma el entonces subdirector de Callejeros, Nacho Medina, el programa muestra "la realidad a borbotones". Lo más importante son sus protagonistas, las vidas anónimas, los héroes y villanos. Callejeros, producido por Molinos de Papel, creó escuela por su característico estilo de grabación, que fue muy imitado. Dejó de emitirse en marzo de 2014.

El equipo de Callejeros lo integran seis reporteros y cuatro operadores de cámara, que "salen a la calle en busca de la realidad", según Carolina Cubillo, creadora del formato (Cit. en Balín, 2007). La dirección coordina todo el proceso de producción: decide el tema, asigna un reportero, elabora el guion y documentación, graban y sobre la marcha cambian o no el rumbo del reportaje, según el material que consigan. De acuerdo con Cubillo, el equipo actúa con plena libertad, aportando "un estilo de autor" en cada reportaje. Lo más importante es la cercanía, el trato humano de los reporteros con los personajes y sus vivencias. En palabras de Cubillo, "el éxito son los reporteros y su sensibilidad para hacer periodismo de calle".

Callejeros potenciaba el dinamismo a través de la cámara al hombro, una banda sonora creada a partir de declaraciones impactantes y un montaje fragmentado más próximo al videoclip que al documental. Cubillo sostiene que Callejeros es un producto que llegó en un momento en el que las televisiones requerían un formato ligado a la realidad sin artificios. Según Manuel Villanueva, director general de contenidos de Mediaset, "si algún día alguien acunó de manera muy osada lo de la telerrealidad, viendo Callejeros habría que acuñar otro término: la tele-verdad. Callejeros es una ventana a la realidad, una mirada circular de $360^{\circ}$ no muy lejos de donde vivo, de donde trabajo, de donde respiro" (en Jabonero, 2011).

Callejeros implantó un estilo de reporterismo cercano a la realidad, obteniendo el respaldo de la audiencia y el reconocimiento de la crítica. Entre otros galardones, obtuvo el Premio Iris al Mejor programa documental (2006), Mejor programa informativo (2007 y 2008), Premio Ondas al Mejor programa de actualidad (2008) y Premio TP de Oro como Mejor programa de reportajes entre 2006 y 2009 , entre otros.

Callejeros viajeros, estrenado el 5 de abril de 2009 con un programa sobre Bombay, contó con el mismo equipo de Callejeros y la misma productora, Molinos de Papel. Sus reporteros visitaban dif erentes países del mundo para conocer de la mano de sus habitantes las ciudades, regiones o países. Callejeros viajeros se inspiró en éxito de Españoles en el mundo de TVE. Tuvo cinco temporadas, hasta la emisión del programa sobre Florencia, el 1 de septiembre de 2013.

Entre agosto de 2008 y septiembre de 2011, Ola, Ola recorría las playas del litoral español para contar historias curiosas y cercanas. El programa narraba cómo, entre sombrillas, cremas solares, neveras portátiles y fiestas nocturnas, los turistas pasan el verano. Los reportajes se emitían con una cortinilla que mostraba el litoral al que dedicaban cada emisión: Atlántico, Cantábrico y Medite- 
rráneo. Sus reportajes mostraban la gastronomía, las costumbres y los lugares más característicos de las zonas de veraneo, e incorporaron secciones de karaoke, chistes, parodias o flash mobs. Producido por Carolina Cubillo y dirigido por Nacho Medina (Molinos de Papel), Ola, Ola cosechó un notable $12,7 \%$ durante la primera de sus cuatro temporadas.

Otro espacio de infoentretenimiento incrementó el papel estrella de la periodista. El 30 de enero de 2009 Cuatro estrenó 21 días, presentado por Samanta Villar. El programa consistía en reportajes sobre la vida de determinados colectivos que una periodista vivía en primera persona. Samanta Villar (Temporadas 1 y 2), Adela Úcar (Temporadas 3, 4, 5 y 6) y Meritxell Martorell (Temporada 7), se pusieron 24 horas diarias durante 21 días en la piel de personas que vivían situaciones extraordinarias: gente con problemas de drogas o juego, vagabundos, desempleados, etc. para mostrar cómo eran sus vidas. En la publicidad del espacio, la protagonista subrayaba: "Hay problemas que solo se entienden cuando se viven en la propia piel y como no es lo mismo contarlo que vivirlo, voy a vivirlo durante 21 días". Dejó de emitirse en julio de 2016, con un 6,9\% de cuota. La web definía 21 días como un espacio de "retos vitales, mundos impactantes, situaciones límite...". Los primeros reportajes abordaron 21 dias entre cartones, ... sin comer, ... fumando porros, ....machacando mi cuerpo. Los temas sociales dieron paso a otros más morbosos en la etapa de Adela Úcar: 21 dias bebiendo alcohol, ... en el mundo del sadomasoquismo, ...en el erotismo, ...en un prostíbulo.

Posteriormente, Samanta Villar dio una vuelta de tuerca a la personalización del género mediante Conexión Samanta, producido por BocaBoca. Tras dos temporadas al frente de 21 días, Villar se embarcó en este espacio donde convivía con personajes durante cinco días antes de una cita importante. Se estrenó el 26 de noviembre de 2010, con éxito de audiencia, y finalizó el 5 de febrero de 2016. En sus dos primeras entregas el título de programa fue 3 Sesenta, pero para evitar problemas con una marca registrada, cambiaron el nombre. Al principio los reportajes se centraron en personajes conocidos, y a partir de la tercera temporada se dio cabida a personas anónimas, combinando historias de temática social, gente corriente y famosos. En 'Pequeñas princesas' mostraron los concursos de belleza infantil. Investigaron las maras de El Salvador y los mareros que quieren cambiar de vida. Y abordaron el mundo de la fuerza bruta en España, mostrando sus excesos. Según Villar, se trata de un formato "que mucha gente no se sentaría a ver porque le parece denso, pero que se sienta a verlo porque le resulta entretenido" (cit. en Jabonero, 2011). El programa acumuló seis temporadas con una audiencia superior a la media de la cadena y dejó de emitirse en febrero de 2016.

Cuatro continuó su apuesta por el reportaje de infoentretenimiento con el lanzamiento de REC reporteros, dirigido y presentado por Jon Sistiaga, y producido por La Quimera. Se estrenó el 23 de abril de 2010 y terminó el 28 de enero de 2011, con dos temporadas de 30 episodios. El espacio pretendía ser una propuesta innovadora en la que el espectador acompañaba a un periodista a lo largo de su investigación. Cada reportero analizaba en profundidad un tema basado en su investigación periodística: David Beriain, Laura Gimeno, Clara Sánchez-Castro, Pere Espinosa, David Escamilla, Nuria Peraire, Angels Molina, y Agustín Pérez. REC reporteros no sólo mostraba el resultado del trabajo periodístico, sino también sus procesos, ya que compartían su experiencia a la vez que iban respondiendo a las cuestiones planteadas.

Entre los reportajes de mayor éxito destacan 'Baby sicarios en Colombia', de David Beriain, y 'Narcoméxico', de Jon Sistiaga, con dos entregas: 'Corrido para un degollado' y 'Alfombra roja para los muertos'. Se trata de reportajes de autor, donde la narración en off ordena las distintas partes de la historia, y la intervención del reportero estructura los testimonios de los protagonistas, las voces de expertos y las localizaciones.

¿Qué hago yo aquí?, producido por Mandarina, se emitió en Cuatro desde el 7 de abril de 2013 hasta el 5 de mayo de 2013. Fue cancelado tras seis episodios, al cosechar un $4 \%$ en sus dos últimas 
entregas. El programa, conducido por Elena Ortega, reflejaba el día a día de un grupo de españoles que por voluntad propia desarrollaban su proyecto vital dentro de un entorno peligroso al que habían terminado adaptándose. ¿Qué hago yo aqui? recorrió enclaves inhóspitos como el desierto de Atacama (Chile), la estepa siberiana, el Cinturón de Fuego del Pacífico, Chernóbil y lugares con un clima de violencia extrema, como Ciudad Juárez o la selva amazónica. El objetivo era mostrar cómo se vive en estos lugares de la mano de los protagonistas anónimos y de Elena Ortega, quien se tenía que adaptar a la dureza de esos peculiares destinos.

Cuatro estrenó En el punto de mira el 26 de julio de 2016, dedicado a temas de actualidad y de investigación, ofreciendo como novedad el formato de las imágenes grabadas en $360^{\circ}$ junto a las panorámicas desde drones y mediante cámara oculta. Producido por Cuarzo, En el punto de mira profundizaba en asuntos polémicos: el negocio de las falsificaciones, la caza 'enlatada' del león en África, la explotación de perros o los intereses de los laboratorios farmacéuticos, entre otros. Los reporteros se desplazaban a diversos puntos del planeta (India, China, Sudáfrica...) para investigar los temas. En el primer reportaje, un equipo se adentra en el centro mundial de las falsificaciones: la ciudad china de Guangzhou, donde se concentran más de 60.000 fábricas que producen falsificaciones de diferente calidad. Una reportera logra adentrarse en los talleres donde se producen copias de bolsos. Mientras, en el puerto de Valencia, un reportero acompaña a los administradores de aduanas marítimas a la caza de cargamentos con falsificaciones.

En el punto de mira puede considerarse un espacio de periodismo de investigación. Cada reportaje se estructuraba en bloques que aportan datos para el análisis circular del tema que se aborda, con un reportero como presentador principal de cada bloque, apoyado en la voz en off. En el punto de mira apela al espectador desde el inicio, con una introducción que expone el estado de la cuestión en un tráiler, mediante una presentación documental con voz en off que describe la problemática y da paso a la presentación de los bloques temáticos a modo de hitos. Los bloques presentan la investigación desde diferentes perspectivas y plantean conclusiones en el cierre de cada hito, que lleva al siguiente bloque o al final del programa. La sexta temporada terminó de emitirse en abril de 2021.

\subsection{La Sexta}

La influencia de Callejeros pronto se hizo notar en la competencia. El 3 de octubre de 2007, la dirección de Callejeros creó Vidas Anónimas para La Sexta, un formato de 50 minutos protagonizado por tres o cuatro personajes. En el piloto intervinieron una médica de urgencias, una localizadora de cine y un pastor evangelista. Según el subdirector, Nacho Medina, la idea surgió tras "conocer personajes de la calle que eran muy poderosos, por ejemplo, un hombre de 80 años, que había sido boxeador, vestía como un punki y recogía basura de los contenedores. Pensamos en seguir 24 horas a esas personas para hacer un programa de reportajes" (Cit. en Vázquez y Román, 2013: 1069).

El estilo de realización de Vidas Anónimas era similar al de Callejeros, caracterizado porque el reportero y el operador de cámara van construyendo cada secuencia con sus personajes. De esta forma, los reporteros se convierten en 'directores de la gente corriente', que a su vez son actores de su propia cotidianidad. Ésta es su esencia: mezclar la realidad dirigida y la espontánea, simulando un continuo monólogo del personaje. Por ejemplo, el programa del 20 de marzo de 2008 narró la vida un joven que pesaba 162 kilos; la primera fotógrafa que publicó en Interviú; y el trabajo de un criador de cerdos.

Vidas Anónimas no utilizaba la voz en off para aportar información adicional; el reportero le sacaba el máximo partido al personaje. Una de sus periodistas, Mónica Palomero, recomienda "que los personajes se sientan relajados con los reporteros, que se olviden de que están siendo grabados" (Cit. en Vázquez y Román, 2013: 1071). "Desde el momento en que se enciende la cámara, el personaje 
está actuando, tanto en sus acciones habituales como en las propuestas por el equipo. Aunque les llamemos actores, los personajes de este programa no lo son, pero interpretan", añade Palomero. La interacción del reportero con los otros personajes permite una producción más económica, mediante secuencias largas grabadas con menor coste y esfuerzo.

Un spin-off de Vidas Anónimas fue Historias con denominación de origen, con reportajes de 20 minutos, producido por Mediapro y dirigido por Liborio Sánchez. Se emitió diariamente desde el 18 de octubre hasta el 9 de diciembre de 2009. El espacio mostraba la cara positiva de la sociedad española, ya que "todos los temas tienen cabida y el lenguaje narrativo no altera la realidad para grabarla. Queremos enseñar a la España feliz porque, aunque sigamos con la crisis, la gente continúa haciendo cosas interesantes" (cit. en Gárgoles, 2009). El equipo, integrado por 16 reporteros, se centraba en buscar historias humanas. "No seguimos la pauta de la actualidad, no hacemos sucesos ni temas de ahora mismo, sino que tomamos el pulso de distintas ciudades. Nos gusta saber qué hace la gente que viaja en metro o va al mercado, o quienes viven con mascotas exóticas. Elegimos los temas que pueden gustar al público, que tienen algo de imprevisible, de original, visual y entretenido", explicaba Liborio Sánchez (cit. en Gárgoles, 2009).

¿Quién vive ahi?, producido por Globomedia y presentado por Raquel Meroño para La Sexta, mostraba los interiores de casas originales de España y del extranjero. Inició su andadura el 17 de enero de 2010 y dejó de emitirse en marzo de 2012 ante su escasa acogida. El 27 de enero de 2012 comenzó la tercera y última temporada con una versión internacional del formato, en lugares como México, Bali, Miami y Brasil. Los dueños narraban en primera persona la historia de las casas donde habitan y descubrían a los telespectadores otras maneras de vivir. Mostraban inmuebles poco convencionales que servían como excusa para conocer a quienes las ocupaban, remarcando aspectos exóticos: los suelos y paredes de cristal de una casa, donde sus inquilinos viven como en un escaparate; una residencia con forma de barco habitada por un marino; una casa-vagón construida en un compartimento de tren; o una casa mudéjar en pleno centro de Sevilla.

La Sexta consiguió innovar con Salvados, presentado por Jordi Évole desde el 24 de febrero de 2008. Desde esa fecha hasta 2015 lo produjo El Terrat y a partir de entonces corre a cargo de Producciones del Barrio. Salvados evolucionó desde sus inicios, cuando predominaba el humor hasta centrarse en los reportajes de investigación. En 2019, Évole fue sustituido por el periodista Gonzo (Fernando González). Salvados se convirtió en uno de los espacios de referencia en La Sexta, con una cuota media de 5,2\% en 2008 y $11,3 \%$ en 2020. Ha obtenido tres Ondas, un Iris y una Antena de Oro, entre otros premios.

En algunos reportajes, Salvados elabora un retrato social de largo recorrido, a través de las aportaciones de individuos anónimos. Otros investigan asuntos polémicos como el accidente del metro de Valencia en 2006 o las presuntas irregularidades en empresas como Mercadona, Inditex o El Pozo. Según Laura Gimeno y Màrius Sánchez (2016), coordinadores de Salvados, la información es el elemento esencial junto con un valioso trabajo producción para elegir localizaciones, gestionar entrevistas y desplazar equipos. Si en sus inicios la mayoría de los profesionales del equipo tenían un perfil de guionista, actualmente cuentan con dos equipos de cinco redactores cada uno que desarrollan hasta cuatro programas a la vez. En cada programa invierten tres semanas de investigación, una de rodaje y dos de postproducción.

Uno de los pilares del éxito es su estructura narrativa y cuidada factura. Al departamento de realización se le atribuye el mérito de potenciar la historia a través de los escenarios, la estética y las transiciones, de modo que la imagen se integra totalmente en la narración: cabeceras tematizadas, músicas adaptadas al tema, cuidada iluminación, localizaciones escogidas, etc. Jordi Évole plantea una mirada propia sobre cada tema. Salvados también aprovecha las redes sociales para difundir sus contenidos e incrementar la participación. 
Estrenado en febrero de 2020, Lo de Évole (Producciones del Barrio para La Sexta) abordó distintas historias personales sobre un tema común con trasfondo social en su primera temporada. El espacio de autor, vertebrado en torno a Jordi Évole, se siguió emitiendo durante el confinamiento provocado por la Covid-19 en un formato especial mediante videoconferencias que contó con el testimonio de personas anónimas que desempeñaron un papel destacado en la pandemia (personal sanitario, sector alimentario, trabajadores del transporte, etc.), así como con representantes de la economía, la política y la cultura en España.

Equipo de Investigación es un programa basado en reportajes de actualidad estrenado en Antena 3 el enero de 2011 en horario de madrugada. El 11 de enero de 2012 pasó a emitirse en el prime time de La Sexta. Con una duración de 60 minutos, está dirigido por Begoña Chamorro y presentado por la periodista Glòria Serra. El número de reporteros en cada programa oscila entre tres y cinco. Sus más de 200 reportajes emitidos han profundizado en sacar a la luz asuntos como la corrupción de Iñaki Urdangarín, el patrimonio de los Franco, los ciberdelitos, la prostitución, la violencia machista o el tráfico de drogas. A menudo los reporteros emplean la cámara oculta para captar escenas comprometidas, acceder a lugares sin ser identificados como periodistas e investigar asuntos turbios. El ritmo ágil de los reportajes emplea una música que transmite tensión constante y recurre a efectos de sonido para realzar los golpes dramáticos. Los subtítulos son esenciales durante el uso de la cámara oculta y en las entrevistas a testigos.

"La persona que narra Equipo de investigación es una cuentacuentos en realidad, pero cuenta cuentos reales", señala Glòria Serra en la web de La Sexta. Con su locución, Serra pretende transmitir dramatismo. La periodista evita el personalismo. "Yo no soy la protagonista porque cuando alguien con cierta presencia penetra en un entorno lo cambia, lo modifica, y la gente no le estaría contestando a una periodista sino a Glòria Serra". Equipo de investigación ha recibido varias querellas judiciales, aunque no ha perdido ninguna. Serra declara: "No somos justicieros, hacemos justicia a la verdad y que esta sobresalga por encima de todo, que no quede impune y no se quede sin voz aquella gente que se siente impotente". El programa es uno de los éxitos de La Sexta, con 12 temporadas.

Encarcelados, producido y presentado por Alejandra Andrade y Jalis de la Serna para La Sexta se estrenó el 5 de septiembre de 2013 y duró una única temporada. En cada reportaje, un periodista y un cámara entrevistaban a españoles encarcelados en distintas prisiones de Latinoamérica para mostrar las duras condiciones de su vida en prisión. A lo largo de diez programas, los reporteros se internaron en las cárceles de Perú, República Dominicana, Bolivia, Colombia, Costa Rica, El Salvador y Brasil, mostrando testimonios sobrecogedores. La cuota de pantalla de Encarcelados evolucionó desde el 12,4\% de su estreno hasta el emitido el 14 de noviembre de 2013, con un 8,2\%.

Enviado especial, producido y presentado por Jalis de la Serna para La Sexta, se estrenó el 11 de febrero de 2016. Es el tercer proyecto para Atresmedia en el que se embarcó de la Serna, esta vez en solitario, tras los éxitos cosechados con Encarcelados y En tierra hostil. Se emitieron tres temporadas, hasta diciembre de 2019. Los reportajes de Enviado especial abordaban las historias peculiares de ciudadanos españoles fuera de nuestras fronteras, tales como el caso de Pablo Ibar, condenado a prisión en Estados Unidos, la inteligencia artificial, el futuro del 3D o la repoblación del planeta. Jalis de la Serna entrevistó a militares que colaboran en misiones bélicas, científicos en centros internacionales o profesoras destinadas al otro lado del mundo. A menudo hizo hincapié en asuntos socialmente relevantes que incidían en la sostenibilidad, el medioambiente, la salud, el desarrollo social y las innovaciones tecnológicas.

La Sexta estrenó en diciembre de 2013 LAB: tal como somos, basado en reportajes realizados mediante cámara oculta que desvelan las reacciones de la sociedad ante diferentes experimentos sociológicos. Cada programa analizó una decena de temas con objeto de investigar la forma de ser de los españoles. $L A B$ : tal como somos arranca con la presentación del planteamiento y, tras la 
grabación del experimento, se desvela el resultado para romper clichés o ratificar actitudes. Analizó las reacciones de la gente ante situaciones muy diversas: el testigo de un robo a un ciego, una actriz entabla conversación con la primera persona que pasa por la calle, o un repartidor entra en una casa de nudistas.

Su director, Paco Jiménez, señalaba: "los temas los vamos trenzando en escaleta, es decir, no resolvemos uno y nos vamos a otro, sino que damos una parte del resultado, avanzamos con otro asunto y luego resolvemos el primero. Es una estructura ágil, con una magnífica realización, postproducción y grafismo del equipo de Mediapro que hacen que el producto final sea muy entretenido. Los temas son muy cercanos, nos podemos ver reflejados en ellos. Queremos ser el espejo de la sociedad" (cit. en Juste, 2013). El espacio finalizó el 5 de enero de 2014, tras la emisión de cuatro capítulos.

Entre mayo y julio de 2017, Cristina Pedroche presentó Dentro de... en La Sexta. La presentadora visitaba lugares como el Hospital La Paz, The Westin Palace, Iberia, El Celler de Can Roca y el Congreso de los Diputados, para mostrar, "con apariencia natural, sin que los reporteros intervengan, las tareas habituales de los equipos profesionales cuya labor es necesaria para el funcionamiento, pero no es visible ni suele ser motivo de atención mediática". Según la web del programa, Dentro $d e . .$. "ofrece una visión inédita de espacios emblemáticos y universos reconocibles. Este formato pone el foco en los equipos humanos que hay detrás, concediendo el protagonismo al trabajo de profesionales anónimos". La narración corría a cargo de Pedroche, que representaba "la mirada del ciudadano". Tras seis emisiones, el programa fue cancelado por su escasa acogida.

La Sexta estrenó Natural, a cargo de Jalis de la Serna y Luz Aldama como productora ejecutiva, el 7 de octubre 2020. Constaba de ocho reportajes para ilustrar la crisis que afrontaba el planeta desde antes de la COVID-19. Según la web del programa, "Natural apela a la imperiosa necesidad de cambiar de rumbo y reconectar con la naturaleza, para evitar el cataclismo global". Los temas abarcaron la contaminación que extermina a ciertas aves, la proliferación de especies invasoras, la amenaza a los acuíferos, la desaparición del lobo o las huellas del cambio climático. Ofrecía un tratamiento divulgativo de la naturaleza y el medio ambiente, mediante entrevistas a expertos, científicos y medioambientalistas, promoviendo la concienciación social.

\section{Conclusiones}

La consolidación del infoentretenimiento televisivo en España ha contribuido a la espectacularización de la información, trascendiendo el ámbito de la telerrealidad y ampliando los recursos del reportaje informativo tradicional. El análisis de 29 espacios de reportajes de infoentretenimiento emitidos por las cadenas generalistas durante el periodo 1990-2020 revela que los canales que dedicaron más tiempo a los reportajes de infoentretenimiento en su programación son La Sexta (once programas) y Cuatro (ocho), seguidos por La 1 de TVE (cuatro), Antena 3 (tres) y Telecinco (tres). La tendencia alcanzó su apogeo entre 2005 y 2010, cuando se estrenaron espacios emblemáticos como Callejeros (Cuatro, 2005) 21 días (Cuatro, 2009), REC reporteros (Cuatro, 2010), Vidas Anónimas (La Sexta, 2007), Salvados (La Sexta, 2008), Comando Actualidad (La 1, 2008) y Españoles en el mundo (La 1, 2009), que tuvieron un largo recorrido y en varios casos, continúan emitiéndose.

La proliferación del reportaje de infoentretenimiento implica un proceso de homogeneización tanto en la temática como en el tratamiento de la realidad como "espectáculo en estado puro" con una elevada dosis de entretenimiento que tiende a uniformizar la oferta televisiva. En el infoentretenimiento, los hechos y los personajes son objeto de tratamientos y enfoques hiperrealistas que distorsionan su realidad original, como apunta Salgado Losada (2011). Los reportajes analizados acentúan la hibridación de géneros, pues combinan la entrevista, la noticia, el documental, la investigación, la crónica o la cámara oculta. De este modo, se incrementa la hibridación de los géneros televisivos 
mediante formatos eclécticos en sus rasgos formales y temáticas (Gordillo et al., 2010). En este contexto, se produce una redefinición del "espacio informativo" y crece la hibridación entre ficción y realidad, entre el periodismo y el entretenimiento.

La mayoría de estos programas de reportajes no son producidos desde los servicios informativos de las cadenas generalistas sino por productoras externas, mediante sus propios equipos de periodistas, cámaras, realizadores, guionistas y productores. Solo seis de los 29 programas analizados son de producción propia: Comando Actualidad (TVE), Espejo Público (Antena 3), Equipo de Investigación, Encarcelados, Enviado Especial y Natural (Atresmedia). Entre las 16 productoras responsables de estos espacios, destacan Producciones del Barrio, Mandarina, Molinos de Papel, Mediapro y Boca Boca.

Los reportajes de infoentretenimiento presentan una estética con estilo documental: la cámara en movimiento que sigue a los personajes, incluyendo planos movidos, iluminación natural y sonido ambiente. Con frecuencia los planos no ofrecen un encuadre óptimo, la cámara se mueve a veces de modo frenético y el montaje conserva saltos de continuidad. El género a menudo apela a la emoción para que el público se sienta implicado: transmite emociones ligadas al drama, al riesgo o al humor, alimentadas por un tratamiento impactante de la imagen, los movimientos de cámara y los efectos sonoros.

Las temáticas más habituales suelen conectar con acontecimientos insólitos (El infiltrado, 21 días, Encarcelados, Conexión Samanta...), lugares dramáticos o con valor especial (¿Quién vive ahí?, Ola, Ola, Españoles en el mundo, Destino: España, ¿Qué hago yo aquí?, El paisano...), conflictos (En tierra hostil, A corazón abierto, Diario de..., REC Reporteros, En el punto de mira...) e investigaciones controvertidas (Equipo de investigación, Al descubierto, Salvados...). Unas veces los reportajes venden ilusión, esperanza y superación; otras, retratan las dificultades y los conflictos con toda su crudeza.

El 'efecto de realidad' también se extiende a la selección de los protagonistas, que suelen ser gente ordinaria, ciudadanos corrientes que a menudo atraviesan situaciones extraordinarias o insólitas (Españoles en el mundo, Comando Actualidad, Callejeros, 21 días, Vidas Anónimas, Salvados...). Al estructurar el relato, el redactor selecciona el elenco de personajes, así como el contenido y los recursos narrativos que permiten transformar sus intervenciones en un reportaje estructurado con dosis de dramatismo y un ritmo adecuado. De este modo, la teatralización de la esfera privada a través del infoentretenimiento persigue convertir la vida cotidiana en un producto televisivo espectacular.

La fluidez narrativa genera la ilusión de que la vida se muestra mediante fragmentos de cotidianidad en cada reportaje. Los profesionales y creadores con frecuencia aluden a su autenticidad y subrayan su carácter documental, reivindicando la autenticidad que potencia la sensación de que el reportero y la cámara transmiten con naturalidad lo que ocurre. Se busca reforzar de este modo la idea de transparencia: el espectador tiene la sensación de asistir al desarrollo de los hechos tal y como se producen, sin interferencia alguna.

El reportero asume un notable protagonismo y suele interactuar directamente con los personajes, transmitiendo su propia implicación. En espacios como 21 días, El Infiltrado, REC Reporteros, Diario de..., Conexión Samanta, Enviado especial, Dentro de, Salvados, Lo de Évole o El Paisano, los reporteros se convierten incluso en la estrella del programa. Su presencia se acentúa de tal modo que participa en la acción como protagonista: aparece en pantalla, transmite sus sensaciones, introduce a los personajes, locuta el off, graba sus entradillas, etc. De este modo, el espectador puede llegar a empatizar con el reportero y sus vicisitudes. 
Este artículo, que analiza la evolución del género de los reportajes de infoentretenimiento a lo largo de tres décadas en las televisiones generalistas españolas, presenta limitaciones en cuanto a los resultados obtenidos. La metodología empleada no permite llevar a cabo un análisis exhaustivo de cada uno de los 29 programas, que arroje resultados más específicos sobre los elementos formales y el tratamiento de los contenidos en la totalidad de los reportajes emitidos en cada temporada. También puede ampliarse a este tipo de reportajes emitidos en las televisiones autonómicas y en otro tipo de canales. Además, los elementos analizados tienden a centrarse en aspectos que a menudo son principalmente descriptivos. Es necesario, por tanto, realizar futuras investigaciones que profundicen en otros aspectos relevantes como el grado de originalidad en la narrativa y los recursos del género, sus condicionantes de producción y presupuestos, así como la recepción por parte de la audiencia.

\section{Bibliografía}

Balín, M. (2007). Entrevista a Carolina Cubillo. Diario Sur. 25 noviembre 2007.

Berrocal Gonzalo, S.; Redondo García, M. y Torres Chico, L. M. (2015). La crisis como espectáculo: el infoentretenimiento en las noticias sobre el rescate bancario en la prensa española de referencia. Communication \& Society, 28, 1-16. https://doi.org/10.15581/003.28.4.1-16

Berrocal Gonzalo, S.; Redondo García, M., Martín Jiménez, V. y Campos Domínguez, E. M. (2014). La presencia del infoentretenimiento en los canales generalistas de la TDT española. Revista Latina de Comunicación Social, 69, 85-103. https://doi.org/10.4185/RLCS-2014-1002

Berrocal-Gonzalo, S. (Ed.) (2017). Politainment: la política como espectáculo en los medios de comunicación. Valencia: Tirant Humanidades.

Brants, K. (1998). Who's afraid of infotainment. European Journal of Communication, 13, $315-$ 335. https://doi.org/10.1177/0267323198013003002

Carrillo, N. (2013). El género-tendencia del infoentretenimiento: definición, características y vías de estudio. En Ferré Pavia, C. (Ed.). Infoentretenimiento. El formato imparable de la era del espectáculo. Barcelona: UOC.

Casero Ripollés, A. y Marzal Felici, J. (eds.) (2011). Periodismo en televisión: nuevos horizontes, nuevas tendencias. Sevilla: Comunicación Social.

Corner, J. (2002). Performing the real: Documentary diversions. Television \& New Media, 3(3), 255-269. https://doi.org/10.1177/152747640200300302

Domínguez-Quintas, S., y Arévalo-Iglesias, L. (2020). La evolución del reportaje en televisión: infoentretenimiento y espectacularización de la realidad. Un nuevo género en el cambio de milenio. Estudios sobre el Mensaje Periodístico, 26(2), 519-528. https://doi.org/10.5209/ esmp.67793

García-Avilés, J. A. (1999). El pseudoperiodismo satírico, un género creciente en la neotelevisión. Diálogos de la comunicación, (55), 18-29.

García-Avilés, J. A. (2007). El infoentretenimiento en los informativos líderes de audiencia en la Unión Europea, Anàlisi, 35, 47-63. https://www.raco.cat/index.php/Analisi/article/view/74254

García-Avilés, J. A. (2009). La desinformación. En Herrero, J. C. (Ed.) Manual de teoría de la información y de la comunicación. Madrid: Universitas, pp. 327-346. 
Gárgoles, P. (2009). Liborio Sánchez vuelve a la tele para dirigir un programa de reportajes, Europa Press, 10 de noviembre de 2009.

Gimeno, L. y Sánchez, M. (2016). Salvados o el éxito de un buen guión periodístico. Institut de Formació Continua. Universidad de Barcelona.

Gómez Martín, M. (2006). Los nuevos géneros de la neotelevisión. Área abierta, (13), 1.

Gómez-Rubio, L., López-Vidales, N., y Blanco-Huerta, M. I. (2020). Reportajes entre la información y el entretenimiento factual: Enviado especial, En el punto de mira y Comando actualidad. El Profesional de la Información, 29(2). https://doi.org/10.3145/epi.2020.mar.02

González Requena, J. (1985). Introducción a una teoría del espectáculo. Revista Telos, 4, 33-44.

Gordillo Álvarez, I., Guarinos, V., Checa Godoy, A., Ramírez Alvarado, M. D. M., JiménezVarea, J., López Rodríguez, De los Santos, F. J., y Pérez-Gómez, M. Á. (2010). Hibridaciones de la hipertelevisión: información y entretenimiento en los modelos de infoentertaiment. Revista Comunicación, 9(1), 93-106.

Gordillo, I. (2009). La hipertelevisión: géneros y formatos. Nuevas y viejas tendencias en la televisión del siglo XXI. Manual de Narrativa Televisiva. Madrid: Síntesis.

Imbert, G. (2008). El transformismo televisivo. Postelevisión e imaginarios sociales. Madrid: Cátedra.

Jabonero, D. G. (2011). Entrevista con Samantha Villar. Fórmula TV, 16 de septiembre de 2011.

Juste, V. (2013). El director de 'LAB: tal como somos': "El programa va a cambiar muchos prejuicios de los españoles". El Televisero. 15 de diciembre de 2013. http://www.eltelevisero. com/2013/12/el-director-de-lab-tal-como-somos-e-2/

La Sexta (2017). Conoce las tripas de los lugares más icónicos del país con Dentro de, la serie documental narrada por Cristina Pedroche. https://www.lasexta.com/programas/dentrode/avances/conoce-las-tripas-de-los-lugares-mas-iconicos-del-pais-con-dentro-de-la-seriedocumental-narrada-por-cristina-pedroche 201705035909f4440cf2461b6df763d8.html

Langer, J. (1998). Tabloid television: popular journalism and the "other news". Londres: Routledge.

Lozano Rendón, J. C. (2004). Espectacularización de la información en noticieros televisivos de Canadá, Estados Unidos y México. Diálogo político, 21, pp. 101-116.

Luzón, V., y Ferrer, I. (2008). Espectáculo informativo en noticies de sociedad: el caso de Madeleine McCann. Trípodos, (22), 137-148.

Mercado Sáez, M. T. (2005). El infoshow con cámara oculta ¿Investigación periodística o espectáculo? Sala de Prensa, 3(85), 20 de octubre.

Nabi, R. (2007). Determining dimensions of Reality: A concept Mapping of the Reality TV Landscape. Journal of Broadcasting \& Electronic Media, 51, 2, 371-390.

Ortells Badenes, S. (2011). La consolidación de los programas de infoentretenimiento en el panorama televisivo español. Fòrum De Recerca, (16), 279-291.

Ortells Badenes, S. (2015). Los magazines de actualidad basados en el infoentretenimiento: nuevos rasgos del lenguaje audiovisual en el periodismo televisivo. Signo y pensamiento, 34(66), 44-61. 
Pérez-Lanzac, C. (2010). Sea corriente y batirá récords de audiencia. El País, 28 de marzo de 2010.

Puelles, M. (2020). Vuelve Equipo de investigación. La Vanguardia, 11 de septiembre. https:// www.lavanguardia.com/television/20200911/483396636697/equipo-investigacion-vuelve-gloriaserra-entrevista.html

Ramírez Alvarado, M. y Gordillo Álvarez, I. (2013). Modelos de tele-realidad: nomenclaturas actualizadas del hipergénero docudramático. Anuario ININCO: investigaciones de la comunicación, 25(1), 339-364.

Redondo García, M. y Campos Domínguez, E. (2015). Implicaciones éticas del infoentretenimiento televisivo. Comunicació: Revista de Recerca i d'Anàlisi, 32(1), 73-89. https:// www.raco.cat/index.php/Comunicacio/article/view/296952

Salgado Losada, A. (2011). Actualidad, humor y entretenimiento en los programas de televisión: de la terminología a la realidad profesional. Trípodos, (27), 59-73.

Saló, G. (2003). ¿Qué es eso del formato? Cómo nace y se desarrolla un programa de televisión. Barcelona: Gedisa.

Segado-Boj, F. (2015). Amarillismo e infoentretenimiento en la información televisiva sobre la crisis económica: el caso de Cuatro TV (2012). Revista Internacional de Historia de la Comunicación, 5, 76-88. https://doi.org/10.12795/RiHC.2015.i05.05

Torrús, A. (2012). Sacamos la cámara y empieza la vida. Público, 17 de febrero de 2012.

Valhondo Crego, J. L. (2011). Sátira televisiva y democracia en España: la popularización de la información política a través de la sátira. Barcelona: UOC.

Vázquez La Hoz, B. y Román Portas, M. (2013). Vidas Anónimas (La Sexta): equilibrio entre realidad auténtica y realidad dirigida. Estudios Sobre el Mensaje Periodístico, 19, 1067-1075. https://doi.org/10.5209/rev_ESMP.2013.v19.42191 